Check for updates

Cite this: RSC Adv., 2019, 9, 2772

Received 31st October 2018

Accepted 22nd December 2018

DOI: $10.1039 / \mathrm{c} 8 \mathrm{ra09029g}$

rsc.li/rsc-advances

\section{One-pot facile simultaneous in situ synthesis of conductive Ag-polyaniline composites using Keggin and Preyssler-type phosphotungstates}

\author{
Abbas Amini, $\mathbb{D} \dagger^{\star a b}$ Marjan Rahimi, (D) $\dagger^{\mathrm{c}}$ Marziyeh Nazari, ${ }^{\mathrm{d}}$ Chun Cheng ${ }^{\mathrm{e}}$ \\ and Bijan Samali ${ }^{\mathrm{a}}$
}

Two heteropolytungstate structures, Keggin $\left(\mathrm{H}_{3} \mathrm{PW}_{12} \mathrm{O}_{40}\right)$ and Preyssler $\left(\mathrm{H}_{14}\left[\mathrm{NaP}_{5} \mathrm{~W}_{30} \mathrm{O}_{110}\right]\right)$, were used to synthesize conductive silver nanoparticle-polyaniline-heteropolytungstate (AgNPs-PAni-HPW) nanocomposites. During the oxidative polymerization of aniline, heteropolyblue was generated and served as the reducing agent to stabilize and distribute AgNPs within "PAni-Keggin" and "PAni-Preyssler" matrixes as well as on their surfaces. The prepared nanocomposites and AgNPs were characterized using UV-visible (UV-Vis) and Fourier-transform infrared spectroscopy (FT-IR), X-ray diffraction (XRD), pore size distribution BET, scanning electron microscopy (SEM), and transmission electron microscopy (TEM). UVVis results showed different stages of the formation of metal NPs embedded in the polymer-HPW composites, and FT-IR spectra presented characteristic bands of PAni, Keggin and Preyssler anions in the composites confirming no changes in their structures. The presence of AgNPs and an intensely crystalline matrix were confirmed by the XRD pattern. The BET surface areas were found to be 38.426 $\mathrm{m}^{2} \mathrm{~g}^{-1}$ for "AgNPs-PAni-Keggin" and $29.977 \mathrm{~m}^{2} \mathrm{~g}^{-1}$ for "AgNPs-PAni-Preyssler" nanocomposites with broad distributions of meso-porous structure for both nanocomposites. TEM and SEM images confirmed that the type of heteropolyacids affected the size of AgNPs. This is the first report that uses Keggin and Preyssler-type heteropolytungstate to synthesize "AgNPs-PAni-HPW" nanocomposites in an ambient condition through a low-cost, facile, one-pot, environmentally friendly and simultaneous in situ oxidative polymerization protocol.

\section{Introduction}

Conductive polymers (CPs) are highly conjugated pi-bonded polymers with unique conductivity as a result of their delocalization of electrons. ${ }^{1-3}$ The extended $\pi$-conjugated electron block, existing in CP molecules, originates their low energy optical transitions and high values of electrical conductivity, mechanical flexibility and surface areas. Significant electron affinity and porous structure of CPs extend their applications to useful substances for the incorporation of nanoparticles (NPs) in polymers. Incorporating metal NPs (MNPs) in organic-inorganic hybrid materials enhances their conductivity and active surface area, due to the facilitation of charge transfer between

${ }^{a}$ Centre for Infrastructure Engineering, Western Sydney University, Kingswood Campus, Bld Z, Locked Bag 1797, Penrith, NSW 2751, Australia. E-mail: a.amini@ westernsydney.edu.au; a.amini@ack.edu.kw

${ }^{b}$ Department of Mechanical Engineering, Australian College of Kuwait, Mishref 13015, Kuwait

'Department of Chemistry, Mashhad Branch, Islamic Azad University, Mashhad, Iran ${ }^{d}$ Mathematics Department, Australian College of Kuwait, Mishref, Kuwait

${ }^{e}$ Department of Materials Science and Engineering, South University of Science and Technology, Shenzhen, China

$\dagger$ These authors had equal roles in this study. the substrate and dispersed NPs in the matrix of hybrid composites. ${ }^{5}$ Conductive polymeric metal NPs (CP-MNPs) composites have shown significant electric, electronic and optical properties, as well as high mechanical flexibility and porosity. ${ }^{6}$ These characteristics have directed CP-MNPs composites to various applications in organic light emission diode (OLED), photovoltaics (PV), and electrochromic devices (ECD). ${ }^{7,8}$

Many textures have been used for CPs, including: polyaniline (PAni), polyacetylene (PA), polythiophene (PTh), polypyrrole (PPy), polyphenylenevinylene (PPV), polyN-vinylcarbazole (PNVC), polyfluorene, polyindole, and their substituted derivatives. These compounds have extended inspiring applications of CPs to rechargeable batteries, microelectronics, sensors and electrochromic displays. ${ }^{9-11}$ Among these textures, PAni has desirable surface area, mesoporous nature, simple preparation, low cost, high catalytic property, high redox and ion-exchange properties, as well as tunable electrical conductivity property (resulted from the flexible - $\mathrm{NH}$ group in its backbone), and good chemical and environmental stability in both air and solutions. ${ }^{11}$ Aniline has three idealized oxidation states: fully reduced state (leucoemeraldine, colorless), fully oxidized state (pernigraniline, purple), and partially oxidized state 
(emeraldine base, blue color, and emeraldine salt, green color). In fact, the conductivity of common semiconductors $\left(10^{-4}\right.$ to $10^{2} \mathrm{~S} \mathrm{~cm}^{-1}$ ), exceeding from the conductivity of common polymers $\left(<10^{-12} \mathrm{~S} \mathrm{~cm}^{-1}\right)$, is originated from the conductivity of emeraldine salt (unsoluble). ${ }^{\mathbf{1 2}}$ The desired properties of electrical conductivity and morphology of PAni nanostructures (different for nanofibers, nanorods, nanotubes, nanowires and nanospheres) can be simply tuned depending on the type of dopant, the type and ratio of oxidant to monomer concentration, the temperature, the acidity of reaction, and the applied polymerization instructions. ${ }^{13}$ PAni has been used both as a filler ${ }^{14}$ and matrix ${ }^{15-18}$ material to achieve the desired properties of hybrid materials. The processability of PAni makes it suitable for the fabrication of polymer matrix of composites by incorporating conducting materials such as $\mathrm{CNTs}^{\mathbf{1 3}}$ and various MNPs as fillers. As a result of these unique properties, PAni can be one of the best platforms for synthesizing nanocomposites through doping with various metallic nanostructures. ${ }^{19}$ Thus, PAni can be one of the most promising active materials suitable for pseudo-capacitor electrodes and super-capacitors, ${ }^{\mathbf{1 9 , 2 0}}$ corrosion inhibitors, electrochromic display structures, electrooptic and smart windows for energy storage in secondary batteries, and a membrane for OLED devices. ${ }^{\mathbf{2 1}}$ Due to its biocompatibility, PAni has been also used in biosensors, cell simulators, bio-actuators and drug delivery systems. ${ }^{2-24}$

CP-NPs composites are synthesized through: electrochemical deposition, ${ }^{9,15,24-26}$ solution or drop casting, ${ }^{27,28}$ layerby-layer self-assembly, ${ }^{29,30}$ and entrapment into sol-gel matrices. ${ }^{16,31-34}$ Most of these conventional methods and materials have limitations and disadvantages including: process complexity, toxicity, high cost, environmental problems, timeconsuming, high energy loss, low efficiency and low doping. ${ }^{6,24}$ Hence, producing modern CP-NPs composites with favorable properties and their corresponding synthesized methods have faced the following challenges. First, the agglomeration of NPs in the polymer matrix that should be avoided by using a suitable solvent. Second, the polymerization, formation and concurrent incorporation of MNPs into a CP matrix that should be spontaneous under ideal conditions (e.g., typical ambient temperature). When the number of steps in sequential reactions is reduced, the fabrication of composite occurs under a higher efficient process. It also receives the same benefits when the reaction is concluded in one containersolution-reagent. Third, the reductive agent for immobilization and stability of NPs that should be non-toxic and environmentally friendly.

To overcome these challenges and provide ideal conditions for simultaneous reactions for polymerization, formation, and homogeneous distribution of metallic NPs, we used heteropolyacids (HPAs) to incorporate into the PAni matrix as dopant anions which not only has strong acidic properties for providing an ideal environment for the polymerization of monomers such as aniline, but it also has high oxidizing potential for readily acquiring and releasing several electrons per molecule.

Generally, HPAs are categorized under anionic metal-oxide clusters of d-block transition metals with high oxidation states $\left(\mathrm{W}^{\mathrm{VI}}, \mathrm{Mo}^{\mathrm{V}, \mathrm{VI}}, \mathrm{V}^{\mathrm{IV}, \mathrm{V}}\right)$ and various size, structure, composition and functions. ${ }^{35}$ Due to their inherent ability (vacant d molecular orbitals), HPAs can undergo fast, reversible, stepwise redox reactions under mild conditions while retaining their intact structures. ${ }^{36}$ Highly negatively charged nature of HPAs is desirable for the molecular dispersion of HPAs on the positively charged backbone of a polymer. This alleviates the aggregation of AgNPs while silver ions are electronically embedded into the PAni matrix. ${ }^{37}$ So, during the oxidative polymerization of aniline, Keggin and/or Preyssler heteropolyanions can transfer electron from aniline to silver ions and, thus, serve as the protonating, reducing and stabilizing agents for the reduction and stabilization of silver ions in the CP framework. The role of HPAs in the synthesis and stabilization of NPs is reviewed in the light of many recent developments of these hybrid materials by various synthesis techniques. Table 1 presents the recent studies on CP-NPs composites using different NPs, CPs and HPAs.

Keggin-type heteropolytungstic acid $\left(\mathrm{H}_{3} \mathrm{PW}_{12} \mathrm{O}_{40}, \mathrm{HPW}\right.$, phosphotungstic acid) belongs to the HPAs group with a central $\mathrm{PO}_{4}$ tetrahedron surrounded by twelve $\mathrm{WO}_{6}$ octahedrons with $T_{\mathrm{d}}$ symmetry (Fig. 1a). It is the most widely used acid and oxidation catalyst for many reactions in industrial processes, such as electrophilic catalyses and oxidation reactions. ${ }^{46}$ Mono$\mathrm{Na}^{+}$-encapsulated Preyssler-type phosphotungstic acid with the formula of $\mathrm{H}_{14}\left[\mathrm{NaP}_{5} \mathrm{~W}_{30} \mathrm{O}_{110}\right]$ consists of a cyclic arrangement of five $\mathrm{PO}_{4}$ tetrahedrons surrounded by thirty $\mathrm{WO}_{6}$ octahedrons (Fig. 1b). They are connected to each other from the edge and corner-sharing oxygen atoms assembled with $D_{5 \mathrm{~h}}$ symmetry where the central cavity is occupied by one sodium ion. ${ }^{\mathbf{4 9 5}}$

Preyssler polyanion possesses distinct properties that make it a unique heteropolyanion in comparison to the rest of HPAs family. These properties are as follow: (1) strong Brønsted acidity due to the presence of 14 acidic protons, which make it as an efficient solid "super acid", (2) high thermal and hydrolytic stability (in pH 0-12 environment), compared to Keggin and Dawson structures, (3) insensitivity to water, (4) recyclability (being green), (5) high oxidation potential, (6) high surface area (Preyssler is the largest polyanion among HPAs), (7) reversible transformation, and (8) solubility in polar and non-polar solvents. Thus, while the $\mathrm{pH}$ (acidity) of the reaction mixture has an intense effect on the successful control of PAni synthesis, ${ }^{51}$ the Preyssler heteropolyanions can be excellent and more effective acidic catalysts than Keggin group to replace the conventional acids, such as $\mathrm{H}_{2} \mathrm{SO}_{4}, \mathrm{HCl}, \mathrm{HNO}_{3}$ and $\mathrm{HF}$, by creating an ecofriendly acidic environment for synthesizing and polymerization of PAni. There is only one report on synthesizing Ag-PAni nanocomposites using Keggin-type phosphomolybdic acid (HPMo) in an aqueous solution by in situ oxidative polymerization method. ${ }^{18}$ In addition, AgNPs-PAni composites were synthesized using Keggin-type phpsphotungstic acid (HPW) through a sol-gel method. ${ }^{16}$ Nevertheless, there is yet no report on utilizing the Preyssler-type for synthesizing CP-NPs composites.

In the present study, we focus on the synthesis of silverincorporated PAni-HPW nanocomposites using Keggin $\left(\mathrm{H}_{3} \mathrm{PW}_{12} \mathrm{O}_{40}\right)$ and mono- $\mathrm{Na}^{+}$-encapsulated Preyssler-type 


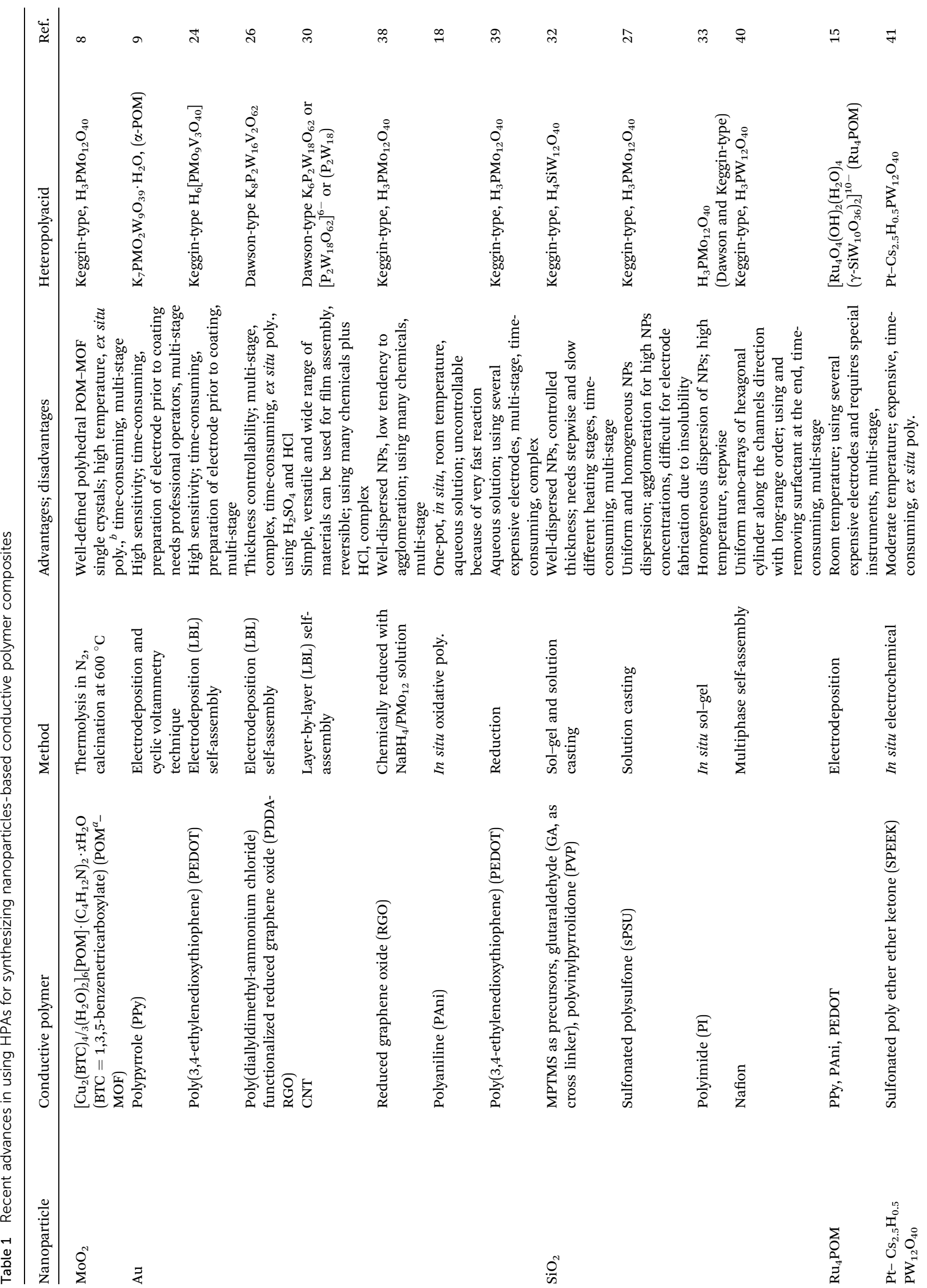




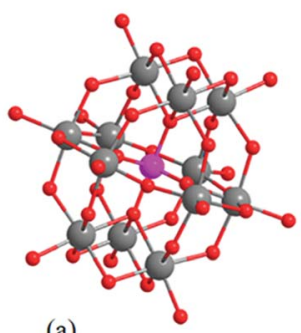

(a)

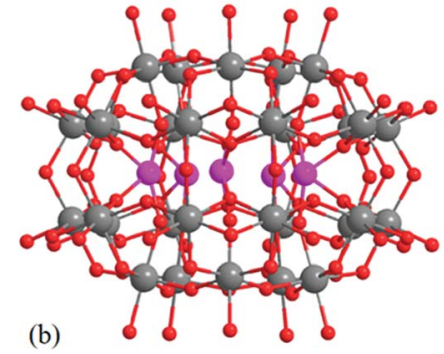

(b)
Fig. 1 (a) Keggin-type structure, (b) Preyssler-type structure.

$\left(\mathrm{H}_{14}\left[\mathrm{NaP}_{5} \mathrm{~W}_{30} \mathrm{O}_{110}\right]\right)$ phpsphotungstic acids, along with their characterizations and comparisons. This report introduces a facile one-pot simultaneous in situ oxidative polymerization synthesis protocol to fabricate "AgNPs-PAni-Keggin" and "AgNPs-PAni-Preyssler" nanocomposites, by significantly lessening the common agglomeration issue in AgNPs. ${ }^{52,53}$ The two green materials, Keggin and Preyssler structures, can serve as: (1) green acid protonating species for oxidative polymerization of aniline monomers by replacing common hazardous liquid acids; (2) dopant anions or stabilizing agents to facilitate the stabilization and distribution of AgNPs in the matrix of PAni nanostructures; and, (3) reducing agents for the reduction of silver ions to stabilize AgNPs decorated in the polymer-HPW matrix. Both synthesized three-component nanocomposites exhibited dispersed and stable spherical silver NPs doped in the polymer (Table 2).

\section{Material and methods}

\subsection{Reagents}

Most of the chemicals were obtained from MERCK, Germany, and used as received without further purifications. Acetonitrile was purchased from SAMCHUN Pure Chemical Co., South Korea, and Cation Exchange Resin, Dowex-50W-x8, was obtained from Sigma Aldrich, USA. The Preyssler-type HPA was prepared in our laboratory. Aqueous solutions were prepared from double distilled deionized water. All the chemical reactions were carried out at room temperature.

\subsection{Synthesis of "AgNPs-PAni-Keggin" composite}

The "AgNPs-PAni-Keggin" nanocomposite was synthesized via a one-step reaction: $0.30 \mathrm{~mL}(3.33 \mathrm{mmol})$ of freshly doubled distilled aniline and $3.48 \mathrm{~g}(1.05 \mathrm{mmol})$ of Keggin-type phosphotungstic acid $\left(\mathrm{H}_{3} \mathrm{PW}_{12} \mathrm{O}_{40}\right)$ were dissolved in $20 \mathrm{~mL}$ acetonitrile; a light orange complex was immediately formed. Then, $1 \mathrm{~mL}(2 \mathrm{M})$ of freshly prepared ammonium persulfate (APS) was added to the mixture drop-wise. Due to the formation of heteropolyblue, the color was changed to an intense blue color which indicated an electron transfer from aniline to Keggin (producing reduced Keggin). To this solution, 7.5 $\mathrm{mL} \mathrm{AgNO}_{3}(0.01 \mathrm{M})$ aqueous solution was added and ultrasonicated for 5 minutes using a TOSHCON sonicator, $40 \mathrm{KHz} 100 \mathrm{~W}$, Germany. The reaction was stirred for 20 hours at room temperature. The mixture was poured onto $100 \mathrm{~mL}$ methanol; an immediate precipitation of the product occurred.

Table 2 Recent methodologies for synthesizing "AgNPs-CP-HPA" composites

\begin{tabular}{|c|c|c|c|c|}
\hline Conducting polymer & Method & Advantages; disadvantages & Heteropolyacid & Ref. \\
\hline \multirow[t]{2}{*}{ Polyaniline (PAni) } & Sol-gel & $\begin{array}{l}\text { Polydispersed NPs; two } \\
\text { irregular morphology of NPs } \\
\text { sizes, excess washing for } \\
\text { removing acid }\end{array}$ & $\mathrm{H}_{3} \mathrm{PW}_{12} \mathrm{O}_{40}$ (Keggin-type) & 16 \\
\hline & $\begin{array}{l}\text { In situ oxidative } \\
\text { polymerization }\end{array}$ & $\begin{array}{l}\text { One-pot, in situ, room } \\
\text { temperature, aqueous } \\
\text { solution; uncontrollable } \\
\text { because of very fast reaction }\end{array}$ & $\mathrm{H}_{3} \mathrm{PMo}_{12} \mathrm{O}_{40}$ (Keggin-type) & 18 \\
\hline Polyvinyl alcohol (PVA) & $\begin{array}{l}\text { Electrospinning and photo- } \\
\text { reduction }\end{array}$ & $\begin{array}{l}\text { Uniform dispersion of } \\
\text { AgNPs, moderate } \\
\text { temperature; ex situ, multi- } \\
\text { stage }\end{array}$ & Keggin-type, $\mathrm{H}_{4} \mathrm{SiW}_{12} \mathrm{O}_{40}$ & 54 \\
\hline Poly- $O$-anisidine & Sol-gel & $\begin{array}{l}\text { Polydispersed NPs, } \\
\text { enhanced thermal stability } \\
\text { up to } 600{ }^{\circ} \mathrm{C} \text {; irregular } \\
\text { morphology of NPs sizes, ex } \\
\text { situ, left-over acid and } \\
\text { oxidant in samples because } \\
\text { of very fast reactionary acid } \\
\text { and oxidant in samples }\end{array}$ & $\mathrm{H}_{3} \mathrm{PMo}_{12} \mathrm{O}_{40}$ (Keggin-type) & 34 \\
\hline Polybenzidine (PBz) & Ultrasound-assisted & $\begin{array}{l}\text { Simple, room temperature; } \\
\text { not very exact method, } \\
\text { broadening XRD peak }\end{array}$ & & 55 \\
\hline Polyaniline (PAni) & $\begin{array}{l}\text { In situ oxidative } \\
\text { polymerization }\end{array}$ & $\begin{array}{l}\text { Room temperature, facile, } \\
\text { one-pot, reproducible, eco- } \\
\text { friendly, simultaneous, } \\
\text { stable AgNPs; low amount of } \\
\text { chlorine in the medium }\end{array}$ & $\begin{array}{l}\mathrm{H}_{3} \mathrm{PW}_{12} \mathrm{O}_{40} \text { (Keggin-type), } \\
\mathrm{H}_{14} \mathrm{NaP}_{5} \mathrm{~W}_{30} \mathrm{O}_{110} \text { (Preyssler- } \\
\text { type) }\end{array}$ & This study \\
\hline
\end{tabular}


The precipitate was centrifuged at $6000 \mathrm{rpm}$ for 5 minutes and repeatedly washed with methanol until the filtrate turned colorless. The precipitate was washed with double distilled demineralized/deionized water three times to remove excessive oligomer. Unreacted heteropoly and oxidant were washed using acetone. The black solid sample (AgNPs-PAni-Keggin) was air dried and placed in a vacuum oven under $80{ }^{\circ} \mathrm{C}$ and stored in a desiccator for further characterizations.

\subsection{Preparation of Preyssler-type sodium 30- tungstopentaphosphate $\left(\mathrm{H}_{14}\left[\mathrm{NaP}_{5} \mathrm{~W}_{30} \mathrm{O}_{110}\right]\right)$}

In a $100 \mathrm{~mL}$ beaker, $40 \mathrm{~mL}$ distilled water was heated to $40-$ $45{ }^{\circ} \mathrm{C}$; then, $33 \mathrm{~g}(100 \mathrm{mmol})$ sodium tungstate dihydrate $\left(\mathrm{Na}_{2} \mathrm{WO}_{4} \cdot 2 \mathrm{H}_{2} \mathrm{O}\right)$ was gradually added while stirring to dissolve thoroughly. The mixture was consolidated with ortho-phosphoric acid ( $25 \mathrm{~mL}, \mathrm{H}_{3} \mathrm{PO}_{4}, 85 \%$ ), and transferred to a $100 \mathrm{~mL}$ flask where it was refluxed for 5 hours. After cooling down to ambient temperature, the content of flask was transferred to a beaker where pulverized potassium chloride $(10 \mathrm{~g} \mathrm{KCl})$ was gradually added to the mixture and stirred for 30 minutes. The resultant light greenish precipitate was filtered and recrystallized in distilled water. After cooling, the needlelike white crystals, which contained Preyssler salt $\left(\mathrm{Na}_{1.5} \mathrm{~K}_{12.5}\left[\mathrm{NaP}_{5} \mathrm{~W}_{30^{-}}\right.\right.$ $\left.\mathrm{O}_{110}\right]$ ), were separated from the mixture by using a Büchner funnel and dried. In the next stage, to prepare Preyssler acid, the needlelike heteropoly crystals were dissolved in distilled water, and passed through a column $(50 \times 1 \mathrm{~cm})$ of Dowex-50W$\mathrm{x} 8$ (cation exchange resin). After evaporating the solvent at $70{ }^{\circ} \mathrm{C}$, the Preyssler acid, $\mathrm{H}_{14}\left[\mathrm{NaP}_{5} \mathrm{~W}_{30} \mathrm{O}_{110}\right]$, was obtained as an off-green solid; it was characterized by IR test (Fig. 2c).

\subsection{Synthesis of "AgNps-PAni-Preyssler" composite}

The "AgNPs-PAni-Preyssler" nanocomposite was synthesized in a one-step reaction: $0.65 \mathrm{~mL}(7.15 \mathrm{mmol})$ of freshly doubled distilled aniline and $3.69 \mathrm{~g}(0.50 \mathrm{mmol})$ of Preyssler acid were dissolved in $30 \mathrm{~mL}$ acetonitrile; white precipitate was immediately formed. Then, $1.3 \mathrm{~mL}$ of freshly prepared APS (2 M) was added to the mixture drop-wise, where, owing to the formation of heteropolyblue, the color was changed to an intense blue color indicating an electron transfer from aniline to Preyssler (producing reduced Preyssler). To this solution, $12 \mathrm{~mL} \mathrm{AgNO}_{3}$ $(0.01 \mathrm{M})$ aqueous solution was added and ultrasonicated for 5 minutes in the sonicator. The reaction was stirred for 20 hours at room temperature. The mixture was poured onto $100 \mathrm{~mL}$ methanol, an immediate precipitation of product occurred. The precipitate was centrifuged at $6000 \mathrm{rpm}$ for 5 minutes and repeatedly washed with methanol until the filtrate turned colorless. After that, it was washed three times with double distilled demineralized/deionized water to remove excessive oligomer. Unreacted heteropoly and oxidant were washed using acetone. The black solid sample (AgNPs-PAni-Preyssler) was air dried, placed in a vacuum oven at $80{ }^{\circ} \mathrm{C}$, and stored in a desiccator for further characterizations.

\subsection{Characterization of AgNPs embedded polyaniline- heteropolytungstate composites}

A UV-Vis spectrophotometer (CARY50, VARIAN Spectrometer, Australia) was utilized to record different stages of the formation of "AgNPs-PAni-HPW" nanocomposite within the wavelength range 200-800 $\mathrm{nm}$. Fourier transform infrared spectra (FT-IR) were recorded by a Nicolet (Thermo) Avatar 370 FTIR
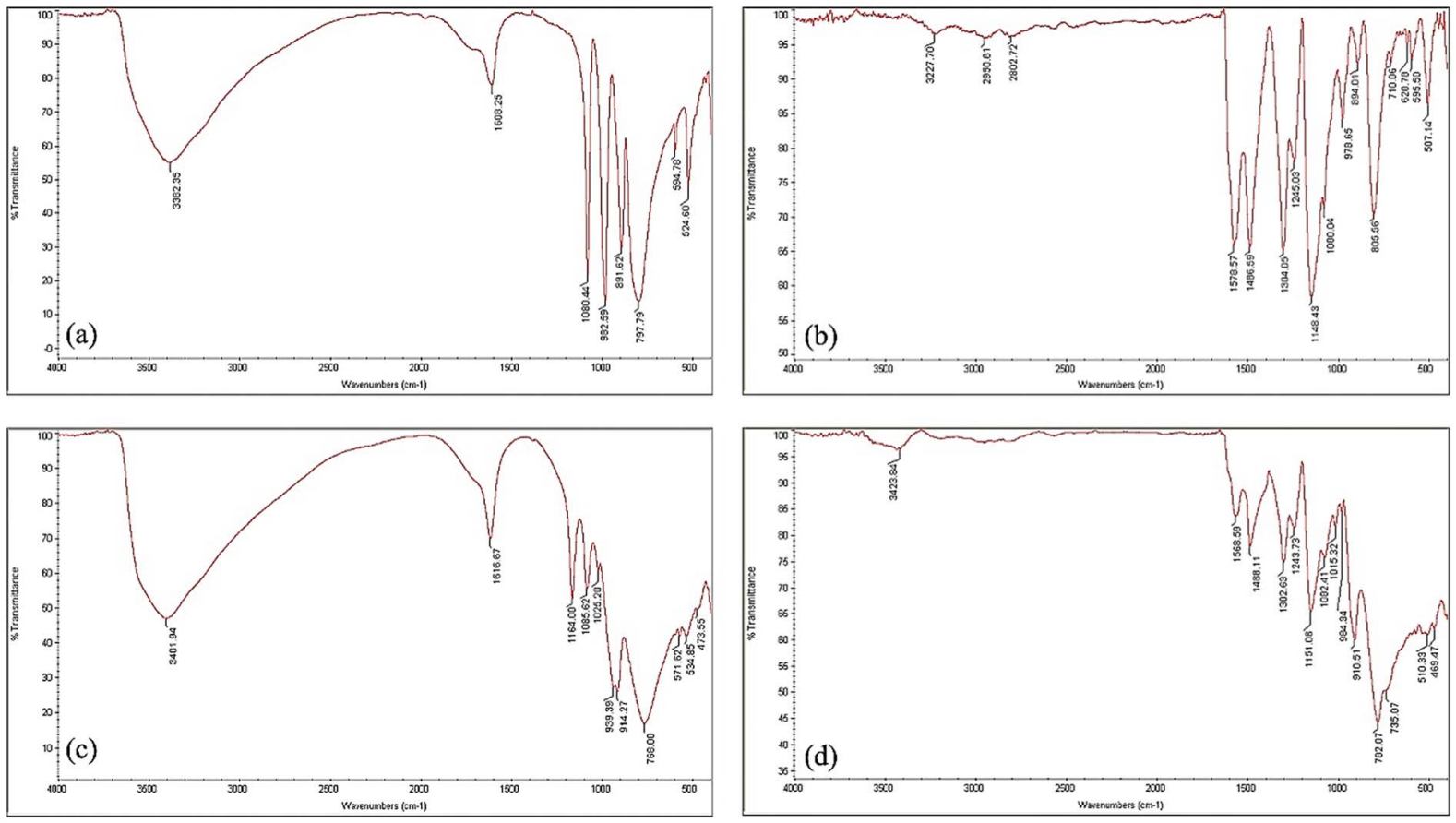

Fig. 2 FT-IR spectra of: (a) pure Keggin-type structure, (b) "AgNPs-PAni-Keggin" nanocomposite, (c) pure Preyssler-type structure, and (d) "AgNPs-PAni-Preyssler" nanocomposite. 
Spectrometer, USA, using the $\mathrm{KBr}$ pellet mode in the region of 4000-400 $\mathrm{cm}^{-1}$. A Transmission Electron Microscope (TEM, PHILIPS, model CM120, Netherland) was utilized at $120 \mathrm{~K}$ accelerating voltage. The Scanning Electron Microscopy (SEM) was carried out by Philips XL30 ESEM, at $20 \mathrm{KV}$ voltage. The XRay Diffraction (XRD) patterns were recorded by a diffractometer, Explorer $\theta-\theta$, GNR, Italy, equipped with a dectris (fast strip) detector and fitted at $0.25 \mathrm{~mm}$ radiation entrance slit, using $\mathrm{Ni}$ filtered $\mathrm{Cu} \mathrm{K} \alpha$ radiation $\left(k=1.5418 \AA\right.$ at $0.01^{\circ}$ scan rate in $\left.2 \theta\right)$. The Brunauer-Emmett-Teller (BET) specific surface area of the samples was examined using PHS-1020 (PHSCHINA), China. The pore size distributions were calculated through the BarrettJoyner-Halenda (BJH) method.

\section{Results and discussion}

In the present protocol, PAni-supported AgNPs, containing Keggin and Preyssler-type phosphotungstic acids, were prepared in a one-step reaction through simultaneous in situ oxidative polymerization of aniline in the presence of APS as the co-oxidant at room temperature. The experimental evidence, which proves the stability and existence of Keggin and Preyssler heteropolyanions incorporated to the PAni matrix, comes from the FT-IR spectra (Fig. 2a-d). In Fig. 2a, the FT-IR spectra of fingerprint bands of bulk HPW Keggin anion, $\left[\mathrm{PW}_{12} \mathrm{O}_{40}\right]^{3-}$, are seen at 1080, 982, 891, 797 and $594 \mathrm{~cm}^{-1}$ which were slightly shifted to the bands at 1080, 978, 894, 805 and $595 \mathrm{~cm}^{-1}$ in correspondence to the FT-IR spectra of "AgNPs-PAni-Keggin" nanocomposite in Fig. 2b, which indicated that HPW retained its Keggin structure. Band shifts are identified as the reflection of strengthening and shortening of Keggin units upon doping in the PAni backbone (Table 3). ${ }^{46,56}$ In addition, Fig. 2 b corresponds to FT-IR spectra of "AgNPs-PAni-Keggin" nanocomposite. This represents the characteristic bands of Keggin in the nanocomposite: the peaks of PAni at $1578 \mathrm{~cm}^{-1}$ and $1486 \mathrm{~cm}^{-1}$ (the deformation modes of benzene rings, benzoid and quinoid rings), $1304 \mathrm{~cm}^{-1}$ (C-N bending, vibration of aromatic amine), $1245 \mathrm{~cm}^{-1}\left(\mathrm{C}-\mathrm{N}^{+\bullet}\right.$ stretching vibrations in the polaron structure representing the existence of conducting protonated PAni), and, $1148 \mathrm{~cm}^{-1}$ (stretching mode of protonated PAni). ${ }^{\mathbf{4 6 , 5 7}, 58}$

The characteristic peaks of pure Preyssler unit, $\left[\mathrm{NaP}_{5} \mathrm{~W}_{30^{-}}\right.$ $\left.\mathrm{O}_{110}\right]^{14-}$, are exhibited at 1164 and 1085, 939, 914, 768 and $534 \mathrm{~cm}^{-1}$ (Fig. 2c). In the IR spectra of synthesized "AgNPsPAni-Preyssler" nanocomposite, peaks are located at 1151 and 1082, 984, 910, 782 and $510 \mathrm{~cm}^{-1}$ (Fig. 2d and Table 4). From the FTIR analysis, slight shifts confirm the existence of strong peaks of pure Preyssler and PAni. A strong electrostatic interaction between Preyssler and PAni matrix exists while the molecular structure of Preyssler anions is preserved during the incorporation with the nanocomposite (despite the larger size of Preyssler structure compared to Keggin). As there are strong covalent bonds in the defined structure of Preyssler molecule between oxygen and tungsten atoms, its structure is maintained after doping, although some deviations occur in its spatial form; this phenomenon is reflected in the slight shifts in IR spectra. Proper distribution of molecular active particles of Keggin and Preyssler heteropoly anions in the PAni nanostructures introduces them as excellent candidates for heterogeneous catalysis applications with enhanced performances. ${ }^{38}$

The optical properties of "AgNPs-PAni-Keggin" (Fig. 3a) and "AgNPs-PAni-Preyssler" nanocomposites (Fig. 3b) were analyzed using the UV-Vis spectrophotometry method at room temperature. Curve (I) in Fig. 3a illustrates the UV-Vis spectrum of Keggin-type solution with no obvious absorbance in the range of $400-800 \mathrm{~nm}$. Curve (II) corresponds to the UV-Vis absorption of blue-colored solution (heteropolyblue) which contains reduced Keggin solution and oxidized aniline after adding APS.

An absorption band at $415 \mathrm{~nm}$ shows the transfer of one electron from aniline to Keggin (due to the electron transition to d orbitals of $\mathrm{W}$ ). The broad weak peak at $700 \mathrm{~nm}$ is ascribed to the overlap of characteristic absorption of $\left[\mathrm{PW}_{12} \mathrm{O}_{40}\right]^{3-}$ and PAni. ${ }^{18}$ Color intensity increased due to the electron transition in the examined substances. Curve (III) shows the spectra of PAni-Keggin mixture to which $\mathrm{AgNO}_{3}$ solution was added to reduce the silver ions to AgNPs. Strong absorption peaks were observed at $\sim 450$ and $\sim 573 \mathrm{~nm}$ because of the excitation of

Table 3 FTIR peak assignment of Keggin structure (bolded) and "AgNPs-PAni-Keggin" nanocomposite

\begin{tabular}{|c|c|}
\hline Wavenumber $\left[\mathrm{cm}^{-1}\right]$ & Peak assignment \\
\hline $3382 \mathrm{~cm}^{-1}$ & O-H stretching \\
\hline$>3227 \mathrm{~cm}^{-1}$ & $\mathrm{~N}-\mathrm{H}$ stretching of PAni \\
\hline $1304 \mathrm{~cm}^{-1}$ & $\mathrm{C}-\mathrm{N}$ bending (vibration of aromatic amine) \\
\hline $1245 \mathrm{~cm}^{-1}$ & $\mathrm{C}-\mathrm{N}^{+\cdot}$ stretching vibrations in the polaron structure representing the existence of conducting protonated PAni \\
\hline $1148 \mathrm{~cm}^{-1}$ & $\mathrm{C}=\mathrm{N}$ stretching mode of protonated PAni \\
\hline $982 \mathrm{~cm}^{-1}$ & $\mathrm{~W}=\mathrm{O}$ stretching mode of exterior $\mathrm{WO}_{6}$ octahedron of pure Keggin \\
\hline $978 \mathrm{~cm}^{-1}$ & $\mathrm{~W}=\mathrm{O}$ stretching shift of Keggin dopped in "AgNPs-PAni-Keggin" nanocomposite \\
\hline 891 and $797 \mathrm{~cm}^{-1}$ & W-O-W stretching mode of corner and edge shared octahedron of pure Keggin \\
\hline 894 and $805 \mathrm{~cm}^{-1}$ & W-O-W stretching shift of Keggin dopped in "AgNPs-PAni-Keggin" nanocomposite \\
\hline $594 \mathrm{~cm}^{-1}$ & P-O bending of pure Keggin \\
\hline $595 \mathrm{~cm}^{-1}$ & P-O bending shift of Keggin dopped in "AgNPs-PAni-Keggin” nanocomposite \\
\hline
\end{tabular}


Table 4 FTIR peak assignment of Preyssler structure (bolded) and "AgNPs-PAni-Preyssler" nanocomposite

\begin{tabular}{|c|c|}
\hline Wavenumber $\left[\mathrm{cm}^{-1}\right]$ & Peak assignment \\
\hline $3401 \mathrm{~cm}^{-1}$ & O-H stretching \\
\hline $3423 \mathrm{~cm}^{-1}$ & $\mathrm{~N}-\mathrm{H}$ stretching of PAni \\
\hline $1302 \mathrm{~cm}^{-1}$ & $\mathrm{C}-\mathrm{N}$ bending (vibration of aromatic amine) \\
\hline $1243 \mathrm{~cm}^{-1}$ & $\mathrm{C}-\mathrm{N}^{+\bullet}$ stretching vibrations in the polaron structure representing the existence of conducting protonated PAni \\
\hline 1164 and $1085 \mathrm{~cm}^{-1}$ & P-O stretching modes of pure Preyssler \\
\hline $782 \mathrm{~cm}^{-1}$ & $\mathrm{~W}=\mathrm{O}$ stretching shift of Preyssler dopped in "AgNPs-PAni-Preyssler" nanocomposite \\
\hline 939 and $914 \mathrm{~cm}^{-1}$ & W-O-W stretching mode of pure Preyssler \\
\hline 984 and $910 \mathrm{~cm}^{-1}$ & W-O-W stretching shift of Preyssler dopped in "AgNPs-PAn-Preyssler" nanocomposite \\
\hline $534 \mathrm{~cm}^{-1}$ & P-O bending of pure Preyssler \\
\hline $510 \mathrm{~cm}^{-1}$ & P-O bending shift of Preyssler dopped in "AgNPs-PAni-Preyssler" nanocomposite \\
\hline
\end{tabular}

surface plasmon resonance (SPR) of AgNPs in "AgNPs-PAniKeggin” nanocomposite, along with the transferring electrons from the internal orbitals (d) of Keggin to Ag ions (Fig. 3a, curve (III)). ${ }^{18,59}$

In Fig. 3b, curves (I) and (II) correspond to the UV-Vis spectra of "AgNPs-PAni-Preyssler" nanocomposite which are nearly similar to the ones for Keggin-type, however, curve (III) differs by a strong absorption band at $415 \mathrm{~nm}$ and a weak band at $\sim 700 \mathrm{~nm}$. Given that each heteropoly structure has a specific redox potential; these differences are important for the reduction of silver NPs where the redox potential should be large enough to reduce and stabilize AgNPs in the polymer matrix. In summary, Preyssler-type HPAs like Keggin could reduce and
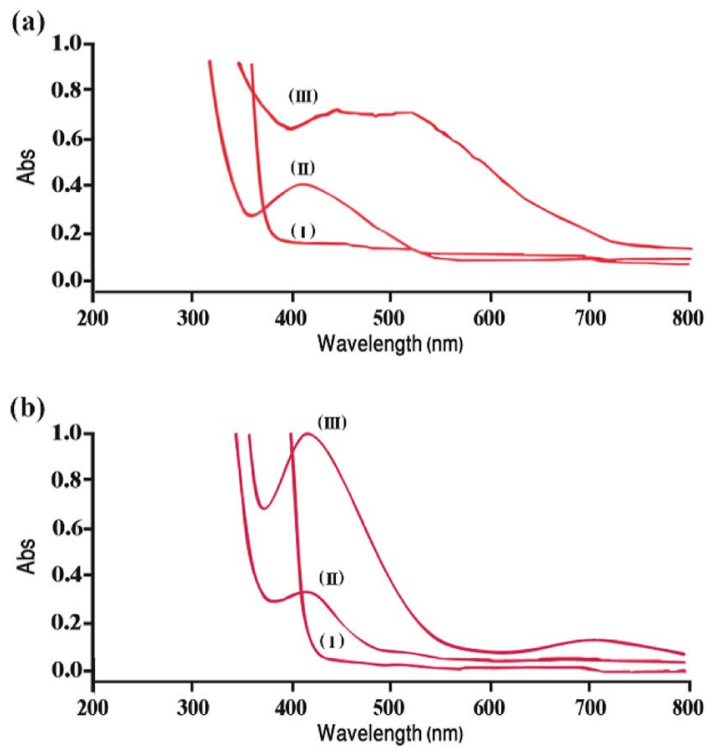

Fig. 3 UV-Vis spectra of (a) "AgNPs-PAni-Keggin" nanocomposite: (I) $10 \mathrm{mmol}$ Keggin-type solution, (II) blue-coloured solution containing Keggin anion and Aniline, (III) after addition of $\mathrm{AgNO}_{3}$ to blue-coloured solution (II); and (b) "AgNPs-PAni-Preyssler" nanocomposite: (I) $10 \mathrm{mmol}$ Preyssler-type solution, (II) blue-coloured solution containing Preyssler anion and aniline, (III) after addition of $\mathrm{AgNO}_{3}$ to bluecoloured solution (II). stabilize AgNPs in the nanocomposite in a one-pot process at the ambient temperature.

SEM method was employed to investigate the morphology and size of AgNPs dispersed in both synthesized "AgNPs-PAniKeggin" (Fig. 4a) and "AgNPs-PAni-Preyssler" (Fig. 4b) nanocomposites. SEM results exhibited highly crystalline, porous and irregular structure intermingled with small islands due to some agglomeration of HPW-doped polymer while very small light spots of AgNPs dispersed in the matrix. The irregular morphology of PAni occurs due to the intermolecular hydrogen bonding as well as the existence of folded PAni chains during the polymerization process. ${ }^{57}$ This property indicates that only a part of Keggin molecules dispersed on the surface of polymer and the rest crystallized on the surface of support (polymer matrix). ${ }^{60}$

In Fig. 5, a clear view of AgNPs dopped in PAni-HPW composites is seen through TEM images. Fig. 5(a and b) for "AgNPs-PAni-Keggin" nanocomposite and Fig. 5(c and d) for "AgNPs-PAni-Preyssler" nanocomposite, respectively, exhibit spherical AgNPs dispersed and stabilized in the "PAni-Keggin" and "PAni-Preyssler" nanocomposite matrixes. TEM micrographs clearly showed the matrix of ashy PAni background with individual intense grayish AgNPs with predominant spherical shape surrounded by polymer support, implying the successful synthesis of AgNPs embedded in PAni. Dispersed and stabilized spherical AgNPs are clearly seen in the TEM images of "PAniKeggin" and "PAni-Preyssler" nanocomposite matrixes without the common agglomeration issue which unfavorably occurs in AgNPs products. ${ }^{18}$ From TEM results, the size range of NPs in

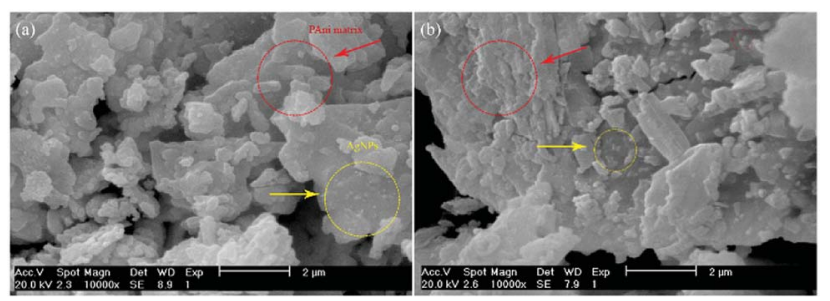

Fig. 4 SEM images of (a) "AgNPs-PAni-Keggin" nanocomposite, and (b) "AgNPs-PAni-Preyssler" nanocomposite. 


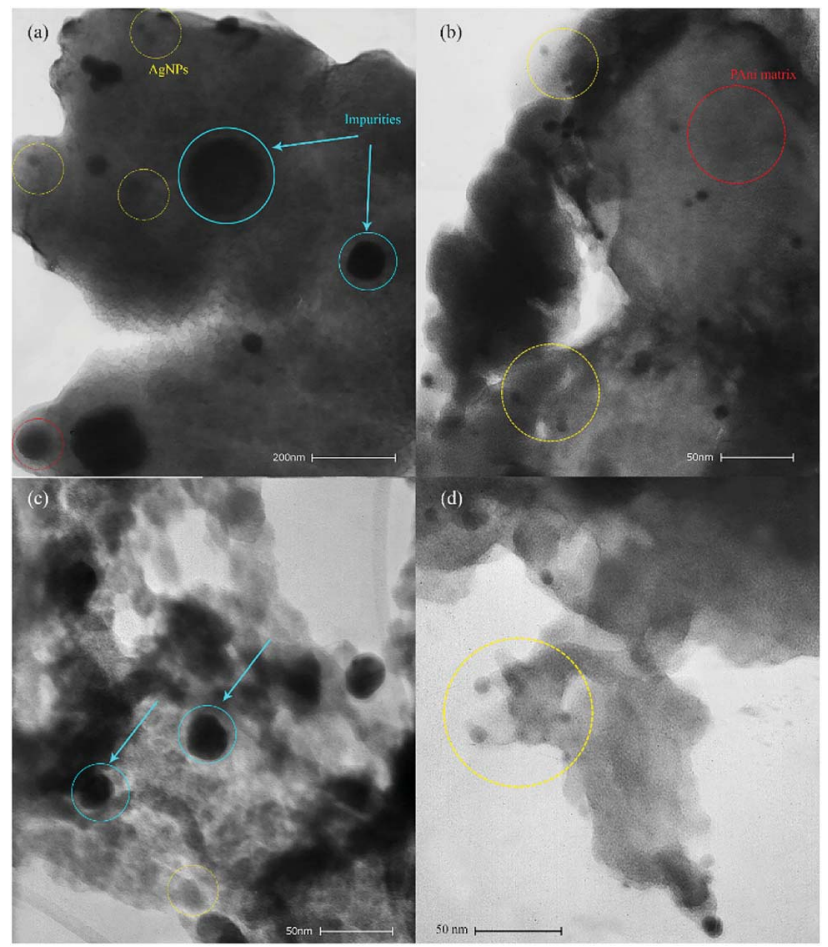

Fig. 5 TEM images of ( $a$ and b) "AgNPs-PAni-Keggin" nanocomposite, and (c and d) "AgNPs-PAni-Preyssler" nanocomposite.

"AgNPs-PAni-Preyssler" nanocomposite is estimated to be smaller than the size of NPs in "AgNPs-PAni-Keggin" nanocomposite. Thus, it can be concluded that the size of NPs was affected by the type of HPA because different HPAs had a specific redox potential and this controlled the size of NPs. As the Preyssler had the highest activity among HPAs (mentioned in Introduction), a faster reduction occurred, which resulted in smaller and more uniform NPs. ${ }^{61}$ The dark highlighted blue circles in Fig. 5 show the impurity contents of $\mathrm{AgNO}_{3}$ or tungsten oxides during the oxidative polymerization of aniline (appeared in XRD results among AgNPs signals).

Generally, AgNPs tend to agglomerate due to small gauges and high surface/volume ratio of NPs. ${ }^{62,63}$ Electrostatic repulsion between Keggin and/or Preyssler molecules arose from
Table 5 XRD peak assignment of AgNPs in "AgNPs-PAni-Keggin" and "AgNPs-PAni-Preyssler" nanocomposites

\begin{tabular}{lll}
\hline Peak assignment (2 theta) & $\begin{array}{l}\text { XRD peaks of } \\
\text { nanocomposites }\end{array}$ & Ref. \\
\hline AgNPs & $38.1^{\circ}, 44.3^{\circ}, 64.2^{\circ}, 77.4^{\circ}$ & 53 \\
Keggin structure & $30.8^{\circ}, 36.5^{\circ}$ & 51 \\
Preyssler structure & $33.7^{\circ}$ & 54 \\
$\mathrm{Ag}_{2} \mathrm{O}$ & $32.1^{\circ}$ & 51 \\
$\mathrm{Ag}_{2} \mathrm{~W}_{2} \mathrm{O}_{7}$ & $32.7^{\circ}$ & 51 \\
$\mathrm{Ag}_{4} \mathrm{P}_{2} \mathrm{O}_{7}$ & $33^{\circ}, 55^{\circ}$ & 51
\end{tabular}

their highly negatively charged units which facilitated the dispersion of HPWs on the positively charged backbone of PAni. Indeed, HPWs structure served as an anchor for the dispersion or trapping AgNPs. So, this alleviated the aggregation of AgNPs while silver ions were electronically introduced into the PAniHPW network and firmly attached to the framework. The strong grafting interaction between the HPW-PAni and AgNPs was found from the nearly thin and transparent PAni matrix doped by the silver NPs where only a few AgNPs were scattered in the PAni matrix. ${ }^{63}$ As a consequence, the attached AgNPs may have ignorable crumpling together in the PAni network. ${ }^{63}$

AgNPs were decorated on both surface as well as the matrix of PAni. ${ }^{35}$ This also indicated that a certain amount of embedded AgNPs could efficiently prevent PAni from stacking during the reduction..$^{63}$ Generally, despite all the studies in the field of AgNPs, their dynamic and complex surface chemistry have not been fully understood. The relationships and interactions in HPA-stabilized NPs with polymer matrix (which are newly emerging hybrid materials), various morphology and different reaction conditions, and wide range of particle size, make it a potential topic for comprehensive studies in the future. ${ }^{64}$

The XRD analysis was served to confirm the presence of AgNPs in both synthesized "AgNPs-PAni-Keggin" (Fig. 6a) and "AgNPs-PAni-Preyssler" (Fig. 6b) nanocomposites. As shown, four peaks were presented at $38.1^{\circ}, 44.3^{\circ}, 64.2^{\circ}$ and $77.4^{\circ}$ which were indexed to Bragg's reflections at (111), (200), (220), and (311) crystalline planes of face-centered cubic (fcc)
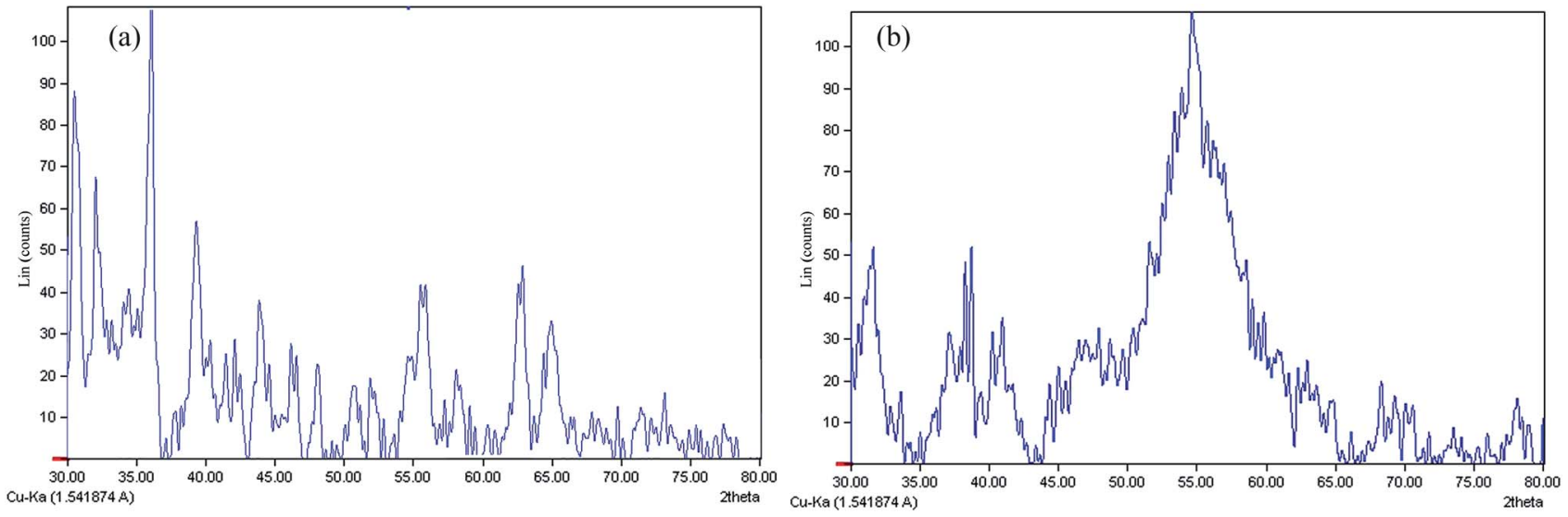

Fig. 6 XRD patterns of (a) "AgNPs-PAni-Keggin" nanocomposite, and (b) "AgNPs-PAni-Preyssler" nanocomposite. 
Table 6 Parametric results from BET analysis for "AgNPs-PAni-Keggin" and "AgNPs-PAni-Preyssler" nanocomposites

\begin{tabular}{lll}
\hline $\mathrm{N}_{2}$ adsorption/desorption & $\begin{array}{l}\text { "AgNPs-PAni-Keggin” } \\
\text { nanocomposite }\end{array}$ & $\begin{array}{l}\text { "AgNPs-PAni-Preyssler" } \\
\text { nanocomposite }\end{array}$ \\
\hline BET surface area & $38.426\left(\mathrm{~m}^{2} \mathrm{~g}^{-1}\right)$ & $29.977\left(\mathrm{~m}^{2} \mathrm{~g}^{-1}\right)$ \\
BJH pore size distribution & $1.26-18.96(\mathrm{~nm})$ & $1.25-19.95(\mathrm{~nm})$ \\
dBJH total pore volume & $0.176\left(\mathrm{~cm}^{3} \mathrm{~g}^{-1}\right)$ & $0.145\left(\mathrm{~cm}^{3} \mathrm{~g}^{-1}\right)$ \\
MP total hole volume & $0.434\left(\mathrm{~cm}^{3} \mathrm{~g}^{-1}\right)$ & $0.543\left(\mathrm{~cm}^{3} \mathrm{~g}^{-1}\right)$ \\
Average pore diameter & $2.244(\mathrm{~nm})$ & $2.235(\mathrm{~nm})$ \\
\hline
\end{tabular}

symmetry of silver metal. ${ }^{65}$ The XRD analysis confirmed that AgNPs were successfully decorated into the crystalline polymer hybrid matrix. Further analysis of the XRD patterns confirmed two peaks at around $30.8^{\circ}$ and $36.5^{\circ}$, related to the characteristic diffraction peaks of Keggin-type HPW. It is concluded from this fact that only a part of Keggin molecules dispersed on the polymer surface and the rest were crystallized on the surface of support ${ }^{66}$ as appeared in the form of irregular structure intermingled with small islands confirmed by SEM. The peaks at around $32.1^{\circ}, 32.7^{\circ}, 33^{\circ}$ and $55^{\circ}$ were related to impurities in $\mathrm{AgNO}_{3}$, such as $\mathrm{Ag}_{2} \mathrm{O}, \mathrm{Ag}_{2} \mathrm{~W}_{2} \mathrm{O}_{7}$ (silver tungsten oxide), $\mathrm{Ag}_{4} \mathrm{P}_{2} \mathrm{O}_{7}$ (silver phosphate) (Table 5). As per the small size, AgNPs can easily participate in the polymerization reactions. ${ }^{63}$ From XRD data, it was evident that the "AgNPs-PAniPreyssler" nanocomposite exhibited broader peaks for NPs than "AgNPs-PAni-Keggin" nanocomposite; this verifies the small crystalline size of AgNPs. For AgNPs with smaller size, the concentration of oxides became larger due to larger surface-volume ratio. ${ }^{63}$ This finding is in-line with the results verified by TEM and BET data on the small-size NPs embedded in the matrix of nanocomposites. It is worthwhile to mention that the size of AgNPs can be estimated from the DebyeScherrer formula. ${ }^{60,65}$

The nitrogen adsorption/desorption isotherms of "AgNPsPAni-Keggin" and "AgNPs-PAni-Preyssler" nanocomposites are
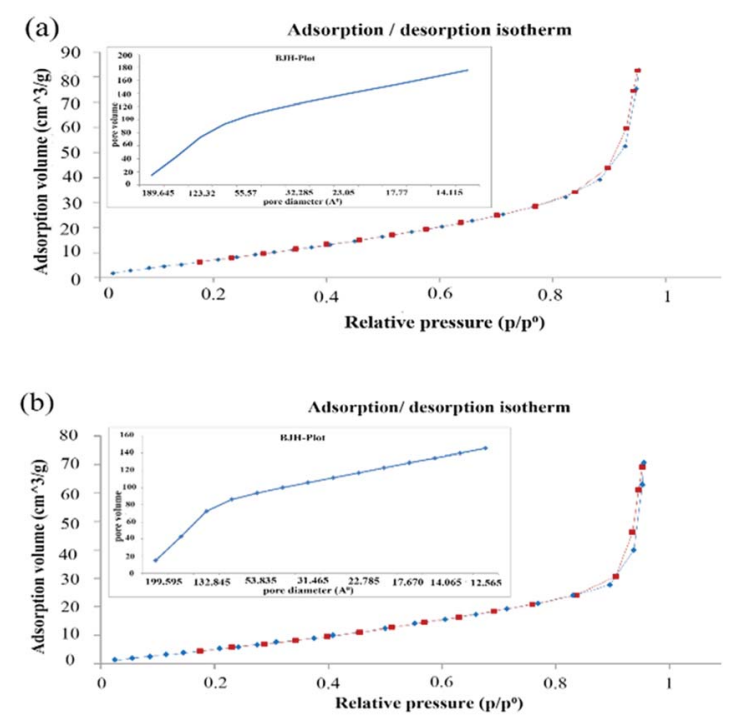

Fig. $7 \quad \mathrm{~N}_{2}$ adsorption/desorption isotherms of (a) "AgNPs-PAni-Keggin" nanocomposite, and (b) "AgNPs-PAni-Preyssler" nanocomposite, along with the inset figure of $\mathrm{BJH}$ pore size distribution. shown in Fig. 7a and b, respectively. As shown in both Fig. 7a and $b$, the $\mathrm{N}_{2}$ isotherm of the as-prepared nanocomposites showed type III adsorption isotherms. The hysteresis loop with a $\mathrm{H} 3$ type is observed for non-rigid aggregates of plate-like particles (slit-shaped pores); ${ }^{67,68}$ in agreement with the SEM data. Besides, there was an additional adsorption step inflection occurred (with slight slope) at relative pressure range $\left(p / p^{0}\right)$ of 0.4-0.6. The meso-pores and step inflection with sharp uptake is observed at relative pressure $\left(p / p^{0}\right)$ of $0.8-1$ which was the indication of the presence of textural macro-pores in both samples ${ }^{46}$ identical with the macro-porous structures observed in SEM. The meso-pore size distribution curves calculated by BJH method are shown in Fig. 7a and b (inset), respectively. Obviously, the samples displayed broad pore size distributions ranging from 1.26 to $18.96 \mathrm{~nm}$ for "AgNPs-PAni-Keggin" and 1.25 to $19.95 \mathrm{~nm}$ for "AgNPs-PAni-Preyssler" nanocomposites (Table 6). The results of physical characterizations showed that micro-porous, meso-porous and macro-pores coexisted in the samples. Micro-pores were more significant (BJH isotherm) as they had high surface area. Both composites exhibited a broad distribution of micro/meso-pores, 12-189 ̊ for "AgNPs-PAniKeggin" nanocomposite (Fig. 7a) and 12-199 ^ for "AgNPsPAni-Preyssler" nanocomposite (Fig. 7b). Here, the average pore diameters were determined as $\sim 2.244 \mathrm{~nm}$ for "AgNPsPAni-Keggin" nanocomposite and $\sim 2.235 \mathrm{~nm}$ for "AgNPsPAni-Preyssler" nanocomposite, nearly similar average pore size. On the other hand, pores with similar diameters in both nanocomposites were mainly in the range of $<10 \mathrm{~nm}$. Furthermore, the Brunauer-Emmett-Teller (BET) surface areas were found as $38.426 \mathrm{~m}^{2} \mathrm{~g}^{-1}$ for the "AgNPs-PAni-Keggin" nanocomposite and $29.977 \mathrm{~m}^{2} \mathrm{~g}^{-1}$ for "AgNPs-PAni-Preyssler" nanocomposites (Table 6).

\section{Conclusion}

A new method was introduced for the synthesis of two novel "AgNPs-PAni-Keggin" and "AgNPs-PAni-Preyssler" conductive nanocomposites through a low-cost, facile, one-pot, environmentally friendly and simultaneous in situ oxidative polymerization protocol at room temperature by using green materials; Keggin and Preyssler-type phosphotungstate. This is the first report that introduces both heteropolytungstates (Keggin and Preyssler-type) as dopants for acid protonating species and oxidative polymerization of aniline monomers. High crystallinity of matrixes was confirmed by XRD and SEM characterizations while TEM analysis showed significantly avoiding the common agglomeration issue in 
AgNPs products. IR results confirmed the existence of HPW as dopant anions that facilitated the stabilization, reduction and distribution of spherical AgNPs in the PAni matrix. BET characterization exhibited highly porous structures for both nanocomposites with the broad distribution of meso-pores with average pore diameters of $\sim 2.244 \mathrm{~nm}$ for "AgNPs-PAni-Keggin" and $\sim 2.235 \mathrm{~nm}$ for "AgNPs-PAni-Preyssler" nanocomposites. The highly protonated degree of PAni with HPW dopants can result in elevated electrical conductivity and flexibility of PAni containing hybrid materials, which can be useful for hydrogen fuel cells, electrodes and catalyses applications.

\section{Conflicts of interest}

There are no conflicts of interest to declare.

\section{Acknowledgements}

The Australian College of Kuwait for funding no. IRC-2017-18SOE-ME-PR01 and PR02 is acknowledged. Special thanks go to Mr Mohammad Akbar Rahimi for his great support for this project.

\section{References}

1 A. J. Heeger, Chem. Soc. Rev., 2010, 39, 2354-2371.

2 A. J. Heeger, Angew. Chem., Int. Ed., 2001, 40, 2591-2611.

3 Y. Zhao, L. Cao, L. Li, W. Cheng, L. Xu, X. Ping, L. Pan and Y. Shi, Sensors, 2016, 16, 1787.

4 R. Zhang, K.-s. Moon, W. Lin and C. Wong, J. Mater. Chem., 2010, 20, 2018-2023.

5 M. Naseri, L. Fotouhi and A. Ehsani, The Chemical Record, 2018.

6 F. Xin and L. Li, Composites, Part A, 2011, 42, 961-967.

7 C. Zhan, G. Yu, Y. Lu, L. Wang, E. Wujcik and S. Wei, J. Mater. Chem. C, 2017, 5, 1569-1585.

8 Y. Zhang, B. Lin, Y. Sun, P. Han, J. Wang, X. Ding, X. Zhang and H. Yang, Electrochim. Acta, 2016, 188, 490-498.

9 A. Babakhanian, S. Kaki, M. Ahmadi, H. Ehzari and A. Pashabadi, Biosens. Bioelectron., 2014, 60, 185-190.

10 K. Dutta, S. Das, D. Rana and P. P. Kundu, Polym. Rev., 2015, 55, 1-56.

11 A. Muñoz-Bonilla, J. Sánchez-Marcos and P. Herrasti, in Conducting Polymer Hybrids, Springer, 2017, pp. 45-80.

12 A. Kumar, L. K. Jangir, Y. Kumari, M. Kumar, V. Kumar and K. Awasthi, J. Appl. Polym. Sci., 2016, 133, 44091.

13 A. Kumar, V. Kumar and K. Awasthi, Polym.-Plast. Technol. Eng., 2018, 57, 70-97.

14 S. B. Teli, S. Molina, E. G. Calvo, A. E. Lozano and J. de Abajo, Desalination, 2012, 299, 113-122.

15 D. Jeon, N. Kim, S. Bae, Y. Han and J. Ryu, ACS Appl. Mater. Interfaces, 2018, 10, 8036-8044.

16 A. Khan, A. M. Asiri, M. A. Rub, N. Azum, A. A. P. Khan, S. B. Khan, M. M. Rahman and I. Khan, Composites Part B, 2013, 45, 1486-1492.

17 A. Khan, A. A. P. Khan, A. M. Asiri, V. Gupta and M. Rathore, J. Mol. Liq., 2016, 216, 646-653.
18 P. Kishore, B. Viswanathan and T. Varadarajan, Nanoscale Res. Lett., 2008, 3, 14.

19 Q. Meng, K. Cai, Y. Chen and L. Chen, Nano Energy, 2017, 36, 268-285.

20 R. Li, C. He, L. Cheng, G. Lin, G. Wang, D. Shi, R. K.-Y. Li and Y. Yang, Composites Part B, 2017, 121, 75-82.

21 S. Bhadra, D. Khastgir, N. K. Singha and J. H. Lee, Prog. Polym. Sci., 2009, 34, 783-810.

22 C. Dhand, M. Das, M. Datta and B. Malhotra, Biosens. Bioelectron., 2011, 26, 2811-2821.

23 H. Zhong, R. Yuan, Y. Chai, W. Li, X. Zhong and Y. Zhang, Talanta, 2011, 85, 104-111.

24 K.-H. Sun, Z. Liu, C. Liu, T. Yu, T. Shang, C. Huang, M. Zhou, C. Liu, F. Ran and Y. Li, Sci. Rep., 2016, 6, 23931.

25 A. A. Ensafi, E. Heydari-Soureshjani, M. Jafari-Asl and B. Rezaei, Carbon, 2016, 99, 398-406.

26 Z. Bai, C. Zhou, H. Xu, G. Wang, H. Pang and H. Ma, Sens. Actuators, B, 2017, 243, 361-371.

27 M. J. Martínez-Morlanes, A. Martos, A. Várez and B. Levenfeld, J. Membr. Sci., 2015, 492, 371-379.

28 D. Zhu, H. Ma, H. Pang, L. Tan, J. Jiao and T. Chen, Electrochim. Acta, 2018, 266, 54-65.

29 C. Zhou, S. Li, W. Zhu, H. Pang and H. Ma, Electrochim. Acta, 2013, 113, 454-463.

30 S. Guo, L. Xu, B. Xu, Z. Sun and L. Wang, Analyst, 2015, 140, 820-826.

31 D. J. Kim, B. M. Lee and S. Y. Nam, Thin Solid Films, 2013, 546, 431-435.

32 U. Thanganathan, J. Membr. Sci., 2016, 517, 100-110.

33 A. Kausar and M. Siddiq, Am. J. Polym. Sci. Eng., 2015, 3, 172182.

34 A. Khan, A. A. P. Khan, A. M. Asiri and M. A. Rub, PLoS One, 2014, 9, e96897.

35 J. Zuo, Z. Zhang, J. Jiao, H. Pang, D. Zhang and H. Ma, Sens. Actuators, B, 2016, 236, 418-424.

36 J. Hu, X. Wu, Q. Zhang, M. Gao, H. Qiu, K. Huang, S. Feng, T. Wang, Y. Yang and Z. Liu, Langmuir, 2018, 34, 2685-2691.

37 L. Zhang, Y. Yang, M. A. Ziaee, K. Lu and R. Wang, ACS Appl. Mater. Interfaces, 2018, 10, 9460-9467.

38 S. Zoladek, I. A. Rutkowska, M. Blicharska, K. Miecznikowski, W. Ozimek, J. Orlowska, E. Negro, V. Di Noto and P. J. Kulesza, Electrochim. Acta, 2017, 233, 113-122.

39 S. S. Hassan, Y. Liu, A. R. Solangi, A. M. Bond and J. Zhang, Anal. Chim. Acta, 2013, 803, 41-46.

40 C. Lin, T. Haolin and P. Mu, Int. J. Hydrogen Energy, 2012, 37, 4694-4698.

41 P. Sayadi, S. Rowshanzamir and M. J. Parnian, Energy, 2016, 94, 292-303.

42 A. A. Khan and U. Baig, Sens. Actuators, B, 2013, 177, 10891097.

43 M. Amirinejad, S. S. Madaeni, K.-S. Lee, U. Ko, E. Rafiee and J.-S. Lee, Electrochim. Acta, 2012, 62, 227-233.

44 X. Fan, W. Yuan, D. H. Zhang and C. M. Li, ACS Appl. Energy Mater., 2018, 1, 411-420.

45 H. Li, X. Zhang, H. Pang, C. Huang and J. Chen, J. Solid State Electrochem., 2010, 14, 2267-2274. 
46 Y. Du, P. Yang, S. Zhou, J. Li, X. Du and J. Lei, Mater. Res. Bull., 2018, 97, 42-48.

47 G. Li, X. Yan, P. Mei, Y. Jiang, Y. Zhang, F. Deng, Y. Xiong and H. Tang, J. Mater. Sci.: Mater. Electron., 2018, 1-7.

48 N. Thakur, S. Das Adhikary, M. Kumar, D. Mehta, A. K. Padhan, D. Mandal and T. C. Nagaiah, ACS Omega, 2018, 3, 2966-2973.

49 A. Hayashi, T. Haioka, K. Takahashi, B. S. Bassil, U. Kortz, T. Sano and M. Sadakane, Z. Anorg. Allg. Chem., 2015, 641, 2670-2676.

50 A. Hayashi, M. N. K. Wihadi, H. Ota, X. López, K. Ichihashi, S. Nishihara, K. Inoue, N. Tsunoji, T. Sano and M. Sadakane, ACS Omega, 2018, 3, 2363-2373.

51 I. Sapurina and J. Stejskal, Polym. Int., 2008, 57, 1295-1325.

52 J. Lu, K.-S. Moon, J. Xu and C. Wong, J. Mater. Chem., 2006, 16, 1543-1548.

53 R. Pasricha, S. Gupta and A. K. Srivastava, Small, 2009, 5, 2253-2259.

54 C. Sui, C. Li, X. Guo, T. Cheng, Y. Gao, G. Zhou, J. Gong and J. Du, Appl. Surf. Sci., 2012, 258, 7105-7111.

55 A. Manivel, R. Sivakumar, S. Anandan and M. Ashokkumar, Electrocatalysis, 2012, 3, 22-29.

56 A. Proń, Synth. Met., 1992, 46, 277-283.
57 A. Kumar, V. Kumar, M. Kumar and K. Awasthi, Polymer Composites, 2017.

58 A. Kumar, V. Kumar, P. Sain, M. Kumar and K. Awasthi, Int. J. Hydrogen Energy, 2018, 43, 21715-21723.

59 K. Awazu, M. Fujimaki, C. Rockstuhl, J. Tominaga, H. Murakami, Y. Ohki, N. Yoshida and T. Watanabe, J. Am. Chem. Soc., 2008, 130, 1676-1680.

60 G. Zhou, T. Cheng, W. Li, Y. Bi and K. Zhen, React. Kinet. Catal. Lett., 2003, 79, 295-302.

61 A. Ayati, A. Ahmadpour, F. F. Bamoharram and M. M. Heravi, Synth. React. Inorg., Met.-Org., Nano-Met. Chem., 2012, 42, 1309-1314.

62 S. Mohammadi, S. Pourseyedi and A. Amini, J. Environ. Chem. Eng., 2016, 4, 2023-2032.

63 J. Zeng, X. Tian, J. Song, Z. Wei, S. Harrington, Y. Yao, L. Ma and Y. Ma, J. Mater. Sci.: Mater. Electron., 2016, 27, 35403548.

64 D. K. Hazra and R. Chatterjee, J. Mol. Struct., 2013, 1045, 139-144.

65 T. Theivasanthi and M. Alagar, arXiv:1111.0260, 2011.

66 D. M. Ruiz, G. P. Romanelli, P. G. Vázquez and J. C. Autino, Appl. Catal., A, 2010, 374, 110-119.

67 K. S. Sing, Pure Appl. Chem., 1985, 57, 603-619.

68 U. Holzwarth and N. Gibson, Nat. Nanotechnol., 2011, 6, 534. 